\title{
17 AN EMPIRICAL RESEARCH IN INTELLIGENT MANUFACTURING: A FRAME BASED REPRESENTATION OF AI USAGES IN MANUFACTURING ASPECTS
}

\author{
Mohammad R. Gholamian, Seyyed M. T. Fatemi Ghomi \\ Department of Industrial Engineering \\ Amirkabir University of Technology, Tehran, IRAN \\ Gholamian,Fatemi\}@aut.ac.ir
}

\begin{abstract}
This paper tries to stimulate empirical research into the overall impacts of intelligent system implementations in manufacturing aspects. To reach this goal, a schema of intelligent applications is provided for each aspect as frame base structure, meaning the knowledge of intelligent applications in that specific aspect. Then, a semantic network is developed for intelligent manufacturing based on hierarchical structure of manufacturing systems to provide Meta knowledge of intelligent manufacturing applications. The paper is concluded with discussions of application performance.
\end{abstract}

\section{INTRODUCTION}

Over the past several years, there has been an increasing trend in use and development of artificial intelligence (AI) in various application areas such as machine learning, planning and robotics, modeling human performance, expert systems, automated reasoning and even in philosophy [17]. In practical fashion, advances in artificial intelligence coupled with reduction in cost of computer hardware and software, have made possible, the introduction of AI at different industrial sectors [15]. But, there are few sectors that have experienced as rapid a push towards this technology as manufacturing. In recent years, the intelligent systems have been widely used in manufacturing aspects. Many of these systems, such as advance manufacturing systems (AMS), computer integrated manufacturing (CIM), flexible manufacturing systems (FMS), manufacturing resource planning (MRPII), $\mathrm{CAD} / \mathrm{CAM}, \mathrm{NC} / \mathrm{CNC}$ numerical control machines are being developed for production and operation management and present a cross fertilization of ideas from manufacturing and AI that is named Intelligent Manufacturing (Int.Man).

Intelligent manufacturing can be broken down in two major areas based on its level of application [1]:

1) Strategic intelligent manufacturing (Str.Int.Man) dealing with what, how and where subjects of production activities.

2) Tactical intelligent manufacturing (Tac.Int.Man) dealing with timing and quality of production activities. 
But unfortunately, the impacts that intelligent systems are having in these environments have not been investigated for the most parts. Most studies on intelligent manufacturing focused on either technical aspects or validation issues. No one has taken a systematic view to this subject and address in implementing these systems.

In this study, several independently basic and important aspects in each area will be discussed systematically. So, the frame based representation has been developed for each aspect such that each frame explains applications of AI implementations in its aspect. In fact, the frames are explanations the knowledge of intelligent applications in their specific aspects. These capsules of knowledge are integrated as Meta knowledge which is the knowledge about the use and control of domain knowledge. The integration is performed using semantic network followed by hierarchical structure of intelligent manufacturing concepts. In fact, the Meta knowledge is explanation of AI implementations in intelligent manufacturing.

The frame of intelligent manufacturing slots with labels, describing usage of intelligent systems as attributes (or properties) and possible values for each attribute. Although a wide range of AI applications can be suggested but specially following ones are selected [3]:

1) rule based reasoning systems (RBR)

2) model based reasoning systems (MBR)

3) case based reasoning systems (CBR)

4) frame based reasoning systems (FBR)

5) probabilistic reasoning (PBR)

6) fuzzy logic

7) neural networks (NN)

8) Meta-heuristics

Then the frame of Int.Man can be developed as follows [28]:

\begin{tabular}{|c|l|}
\hline \multicolumn{2}{|l|}{ Int.Man Frame } \\
\hline Super Class & \multicolumn{1}{|c|}{ Intelligent Systems, Manufacturing } \\
\hline Sub Class & \multicolumn{1}{|c|}{ Str.Int.Man, Tac.Int.Man } \\
\hline RBR & Rule Base, Hybrid Systems \\
\hline MBR & Model Base, Hybrid Systems \\
\hline CBR & Case Base, Hybrid Systems \\
\hline FBR & Frame Base, Hybrid Systems \\
\hline PBR & Bayesian Reasoning, Dempster-Shafer Evidence Logic, Hybrid Systems \\
\hline FUZZY & $\begin{array}{l}\text { Fuzzy Rule Base, Fuzzy Case Base, Fuzzy Frame Base, Fuzzy Operation } \\
\text { Research (FOR), Fuzzy Clustering, Fuzzy Numbers, Hybrid Systems }\end{array}$ \\
\hline NN & $\begin{array}{l}\text { ART family networks, Hopfield networks, Boltzmann Machine, Kohonen } \\
\text { networks, Feedforward networks, Time Delay Neural Networks (TDNN), } \\
\text { Maximum Neural Networks (MNN), Fuzzy Neural Networks (Neuro-Fuzzy) }\end{array}$ \\
\hline Heuristic & $\begin{array}{l}\text { Genetic Algorithm (GA), Simulated Annealing (SA), Tabu Search (TS), Ant- } \\
\text { Colony (ACO), }\end{array}$ \\
\hline
\end{tabular}

In The next sections, the frame base of each manufacturing aspect will be described. The paper is concluded to Meta knowledge of intelligent manufacturing and descriptions about the range of applications 


\section{STRATEGIC INTELLIGNT MANUFACTURING FRAME (Str.Int.Man)}

In this s ection three a spects, which a re directly related to strategic manufacturing operations, will be described as follows:

\subsection{Aggregate Planning (AP) Frame}

Aggregate planning (AP) is an OR model of production planning. The major aim of AP is to determine aggregate quantity of product, for each time period in a future interval of time (called planning horizon), such that minimum total cost is obtained.

Intelligent systems are generally used to generate decisional rules. Rules are utilized to establish production rate, workforce level required, overtime requirements, inventory level, capacity and costs as a rule base aside with mathematical model. In fact, the rule base is used to be auxiliary of mathematical model. HMMS (Holt, 1960) is a sample of such systems.

In addition, rules can be defined fuzzily using linguistic variables and values. Rinus developed fuzzy rules for production and workforce level in HMMMS such as follows [30]:

IF $D_{t}$ is VH AND $I_{t-1}$ is SL AND $W_{t-1}$ is RH THEN $P_{t}$ is SH

IF $D_{t}$ is RH AND $I_{t-1}$ is VL AND $W_{t-1}$ is SL THEN $\Delta W_{t}$ is Positive

In Summarize of above explanations, the frame base of "aggregate planning" will be illustrated as follows:

\begin{tabular}{|c|c|c|c|}
\hline Object Name: & \multicolumn{2}{|c|}{ Aggregate Planning (AP) } & \\
\hline Class: & \multicolumn{2}{|c|}{ Str.Int.Man } & \\
\hline \multirow[t]{8}{*}{ Properties: } & RBR & & (Holt, 60) \\
\hline & MBR & & 8 \\
\hline & CBR & & $\theta$ \\
\hline & FBR & & $\theta$ \\
\hline & PBR & & $\varnothing$ \\
\hline & FUZZY & Fuzzy & MS (Rinus, 82) \\
\hline & NN & & $\varnothing$ \\
\hline & Heuristics & & $\varnothing$ \\
\hline
\end{tabular}

\subsection{Facility Location (FL) Frame}

Facility location is the subject of locating one or more new facilities with respect to existing facilities; such that minimum transportation cost is provided [10]. There are various applications of intelligent systems in facility location problems:

- Fuzzy logic is used in definition of discrete location problems as fuzzy integer programming (FIP) models.

- Meta-heuristics are widely used in quadratic assignment problems (QAP) and facility layout problems. Since the QAP is familiar with TSP, and is graded as NP-Complete problems, various GA, SA, TS and ACO methods are developed 
in this context. In addition, an application of neural networks (i.e. MNN) is also developed in this context.

- Finally, rule based systems are used in layout and material handling problems. In former case, the rules are defined based on the frames of material handling devices such as follows [10]:

IF (material is of unit load type) AND (truck.load/unload level is between 30 and 45 feet) AND (truck.load is less than $2500 \mathrm{lb}$ ) THEN (side-loading outrigger truck is desired)

In Summarize of above explanations, the frame base of "facility location" will be illustrated as follows:

\begin{tabular}{|c|c|c|c|}
\hline Object Name: & \multicolumn{2}{|c|}{ Facility Location (FL) } & \\
\hline Class: & & Str.Int.Man & \\
\hline \multirow[t]{8}{*}{ Properties: } & RBR & $\begin{array}{r}\text { FADES (Fisher \& No } \\
(\mathrm{He} \\
\end{array}$ & $\begin{array}{l}\text { EXIT (Malmborg, 89), KBML } \\
\text { \& Kusiak, 90) }\end{array}$ \\
\hline & MBR & & $\varnothing$ \\
\hline & CBR & & $\varnothing$ \\
\hline & FBR & & $\varnothing$ \\
\hline & PBR & & $\varnothing$ \\
\hline & FUZZY & \multicolumn{2}{|c|}{ FIP (Darzentas, 87) } \\
\hline & NN & \multicolumn{2}{|c|}{ MNN (Tsuchiya et. al, 96) } \\
\hline & Heuristics & \multicolumn{2}{|c|}{ GA, SA, TS, ACO } \\
\hline
\end{tabular}

\subsection{Forecasting (FC) Frame}

Forecasting is the prediction, projection or estimation of the occurrences of uncertain future events or levels of activity. In manufacturing, forecasting is used to predict changeable circumstances such as revenues, costs, profits, prices, technological changes and (in most cases) demand [27].

The model bases are the most eminent systems developed in forecasting aspect. The system includes certain numerous forecasting models and specific models in the scope of brands to provide the analysis capability.

But often no computer-based model can easily incorporate all that is needed to make a sound business decision. In such cases, rule bases can be used to capture the basic judgments that are necessary in forecasting systems. Express is a sample of such RBR systems.

Unfortunately, these systems are very data intensive and data processing is very difficult. Instead, fuzzy rule base can be used with linguistic interpretation. The fuzzy knowledge can be acquired either form experts linguistically or with a set of historical data using Sugeno rule based system. In addition a hybrid of fuzzy rule base and MBR can be used to support both specifications.

Finally some applications of neural networks are developed in forecasting problems as Neuro-identification of time series [13]. Temporal processing networks specially TDNN [9] and simple feedforward networks are sample of such applications.

In Summarize of above explanations, the frame base of "forecasting" will be illustrated as follows: 


\begin{tabular}{|c|c|c|}
\hline \multirow{2}{*}{$\begin{array}{l}\text { Object Name: } \\
\text { Class: }\end{array}$} & \multicolumn{2}{|c|}{ Forecasting (FC) } \\
\hline & & Str.Int.Man \\
\hline \multirow[t]{8}{*}{ Properties: } & RBR & Express (Manzano, 90) \\
\hline & MBR & Model Base, Model Base \& Fuzzy Rule Base \\
\hline & CBR & $\varnothing$ \\
\hline & FBR & $\varnothing$ \\
\hline & PBR & $\varnothing$ \\
\hline & FUZZY & Fuzzy Rule Base, Fuzzy Rule Base \& Model Base \\
\hline & NN & TDNN(Lang \& Hinton, 88), Feedforward (Billings, 92) \\
\hline & Heuristics & $\varnothing$ \\
\hline
\end{tabular}

Now, using above frame bases and based on inheritance rule, the parent frame of strategic intelligent manufacturing can be illustrated as follows:

\begin{tabular}{|c|c|}
\hline \multicolumn{2}{|c|}{ Str.Int.Man Frame } \\
\hline RBR & Rule Base \\
\hline MBR & $\varnothing$ \\
\hline CBR & $\varnothing$ \\
\hline FBR & $\varnothing$ \\
\hline PBR & Model Base, Model Base \& Fuzzy Rule Base \\
\hline FUZZY & Fuzzy Rule Base, FOR, Fuzzy Rule Base \& Model Base \\
\hline NN & MNN, TDNN, Feedforward \\
\hline Heuristics & GA, SA, TS, ACO \\
\hline
\end{tabular}

\section{TACTICAL INTELLIGNT MANUFACTURING FRAME (Tac.Int.Man)}

In this section, six important aspects are selected to be discussed as efficient aspects of tactical intelligent manufacturing:

\subsection{Scheduling (SCH) Frame}

The main aim of scheduling is allocation of resource overtime to perform a collection of tasks. Scheduling itself includes a set of various subjects such as single machine problem, parallel machine problems, flow shop scheduling, job shop scheduling, project scheduling, FMS scheduling. Most of the papers published in AI usages in manufacturing aspects, are commonly related to this aspect.

In $\mathrm{j}$ ob s hop s cheduling, there a re a wide $\mathrm{r}$ ange of heuristic $\mathrm{r}$ ules developed in various areas such as Lisp, Prolog, Itp, OPS5, and Smalltalk [12]. In addition various RBR, FBR and fuzzy RBR systems are developed for various job shop scheduling problems [19-24]. Following is a sample of FBR rules developed on object-oriented fashion:

IF job[i].time < job[j].time AND job[i].duedate > job[j].duedate THEN job[i] precedes job[j]

Fuzzy rule bases are also used in other subjects. In FMS, fuzzy rules are applied in release and machine scheduling; similar to following rule [30]:

IF waiting time is long AND slack time is short THEN date criterion is urgent (0.5).

In addition fuzzy numbers are used in project scheduling instead of PERT networks. 
But since, most of scheduling problems are NP-Complete, a wide range of Meta heuristic development methods and neural network optimization methods [5], are used in this context.

In Summarize of above explanations, the frame base of "scheduling" will be illustrated as follows:

\begin{tabular}{|c|c|c|}
\hline \multirow{2}{*}{$\begin{array}{l}\text { Object Name: } \\
\text { Class: }\end{array}$} & \multicolumn{2}{|r|}{ Scheduling (SCH) } \\
\hline & & Tac.Int.Man \\
\hline \multirow[t]{8}{*}{ Properties: } & RBR & $\begin{array}{l}\text { OPT (Jacobs, 83), ISIS (Fox, 83), PATRLARCH (Morton et } \\
\text { al. 84), MARS (Marsh, 85), PEPS (Robbins, 85), RPMS } \\
\text { (Lipiatt \& Waterman, 85), OPIS (Dw \& Smith, 86), } \\
\text { PLANEX (Zozaya \& Gorostiza, 89), SURE (Thalman \& } \\
\text { Sparn, 90), HESS (Deal et al, 92), ESRA (Solotorevsky, 94) }\end{array}$ \\
\hline & MBR & $\varnothing$ \\
\hline & CBR & $\varnothing$ \\
\hline & FBR & $\begin{array}{l}\text { Enterprise (Marlone, 83), Yams (Parunall, 86), CORTES (Fox } \\
\text { \& Sycora, 89), KBMS (Cholawsky, 90), PARR (McLean, 91) }\end{array}$ \\
\hline & PBR & $\varnothing$ \\
\hline & FUZZY & $\begin{array}{l}\text { OPAL (Bensana, 88), Fuzzy PERT (Prade, 79), Fuzzy } \\
\text { FMS (Hintz \& Zimmermann, 89), FLES (Turksen, 93) }\end{array}$ \\
\hline & $\mathbf{N N}$ & Hopfield network, Kohonen network \\
\hline & Heuristics & GA, SA, TS, ACO (McMullen, 2001) \\
\hline
\end{tabular}

\subsection{Inventory Control (INV) Frame}

The inventory models are developed to response two important questions:

1) How much (quantity) to order [Q]

2) When to order [LT].

There are various inventory models developed based on marketing problems. In addition some inventory systems are developed which are the complex of various marketing subsystems. MRP (material requirement planning), MRP II (material resource planning) and ERP (enterprise resource planning) are samples of these integrated systems [27].

Since the inventory models are widely developed in various marketing subjects, various intelligent systems are developed for approximately all reasoning systems. Specially FBR systems are successfully used in MRP II and ERP systems [12], [22] and CBR systems are successfully used in inventory planning [23-24]. Following is sample of inventory fuzzy rules:

IF the current inventory level is much higher than the preferred level AND the direction is decreasing at medium rate THEN production rate to be moderately slowed down.

In addition, fuzzy mathematical models are developed for various inventory models under uncertainty conditions. As an example it can be mentioned to fuzzy aggregate inventory planning with fuzzy numbers which is solved based on Bellman-Zadeh's rule of conjunction [30].

In Summarize of above explanations, the frame base of "inventory control" will be illustrated as follows: 


\begin{tabular}{l} 
Object Name: \\
Class: \\
$\qquad$\begin{tabular}{|c|c|}
\multicolumn{2}{c|}{ Inventory Control (INV) } \\
\hline Properties: & Tac.Int.Man \\
\hline MBR & NTELLECT (AICORP), NCR, ADS \\
\hline CBR & $\varnothing$ \\
\hline FBR & Case Base \\
\hline PBR & MAPLEX (Walls \& Gilbert, 89) \\
& PAREX-CO (Martins \& Wedel, 90) \\
\hline FUZZY & FDP (Sommer, 81), FMIP ( Kaprzyk \& Staniewski, 82) \\
\hline NN & FLP/FIP (Zimmermann \& Pollatschek, 84), FNLP \\
\hline Heuristics & $\varnothing$ \\
\hline
\end{tabular} \\
\hline
\end{tabular}

\subsection{Quality Control (QC) Frame}

Quality control is application of some statistical techniques to control the production process and improve quality of products with minimum cost. Generally, control charts and acceptance sampling plans are the well-known techniques used in quality control. Recently new concepts such as QFD, TQM, quality assurance (QA), six sigma and ISO standards are successfully used as quality concepts.

Since the structure of quality control is essentially statistical, the Bayesian reasoning can be used in decisional levels [26]. In addition, acceptance sampling plan can be preformed using CBR systems; the historical rejections are saved as cases and then the retrieval process determines acceptance or rejection of inspection. Quality control can be defined fuzzily using fuzzy numbers and fuzzy rules in the structure of quality techniques; the control limits in fuzzy control charts and acceptance/rejection rules in fuzzy sampling plan may be defined fuzzily instead of using crisp values.

Finally as marginal application, neuro-fuzzy and feedforward neural networks are used to train monitoring sensors. The method is successfully used in CNC machines to reach real time machining control [2] and machine condition monitoring [11].

In Summarize of above explanations, the frame base of "quality control" will be illustrated as follows:

\begin{tabular}{ll|}
\hline Object Name: & \multicolumn{2}{|c|}{ Quality Control (QC) } \\
Class: & \multicolumn{2}{|c|}{ Tac.Int.Man } \\
& \multicolumn{2}{|c|}{ Properties: } & RBR & $\varnothing$ \\
\hline MBR & $\varnothing$ \\
\hline CBR & Case Base \\
\hline FBR & $\varnothing$ \\
\hline PBR & Bayesian Reasoning \\
\hline FUZZY & Fuzzy Rule Base, Fuzzy Numbers \\
\hline NN & Feedforward (Jan, 92), \\
& Neuro-fuzzy (Javadpour \& Knapp, 03) \\
\hline
\end{tabular}




\subsection{Maintenance (MTC) Frame}

Maintenance is a branch of quality control with the aim of maintaining the currently available machinery and e quipment to a void failures and to i mprove a pplicability and reliability of facilities. The maintenance models can be classified as follows:

1) Decision models in facility replacement.

2) Inspection models

3) Decision models in partial and fundamental maintenance.

Generally the models are statistical structure and very complex. So, probabilistic reasoning methods can be used in decisional levels successfully. On the other hand, the various models can be saved in model base and then the reasoning is performed using o nline information of machine situation [19]. In c ontrast, RBR systems a re generally used in operational levels [22]. Following, is sample of such rules:

IF main spindle does not turn after switching on, THEN failure will be located on

Similarly case bases are used in operational levels as diagnosis systems. Case bases a re very powerful in diagnosis processes [25] s pecially when the sy stem is developed using fuzzy neural networks [16].

Finally maintenance models can be defined fuzzily in possibility conditions instead of probability conditions. So, fuzzy dynamic programming models (FDP) or maintenance models with fuzzy numbers can be developed and then is solved using fuzzy arithmetic.

In S ummarize of a bove explanations, the frame base of "maintenance" will be illustrated as follows:

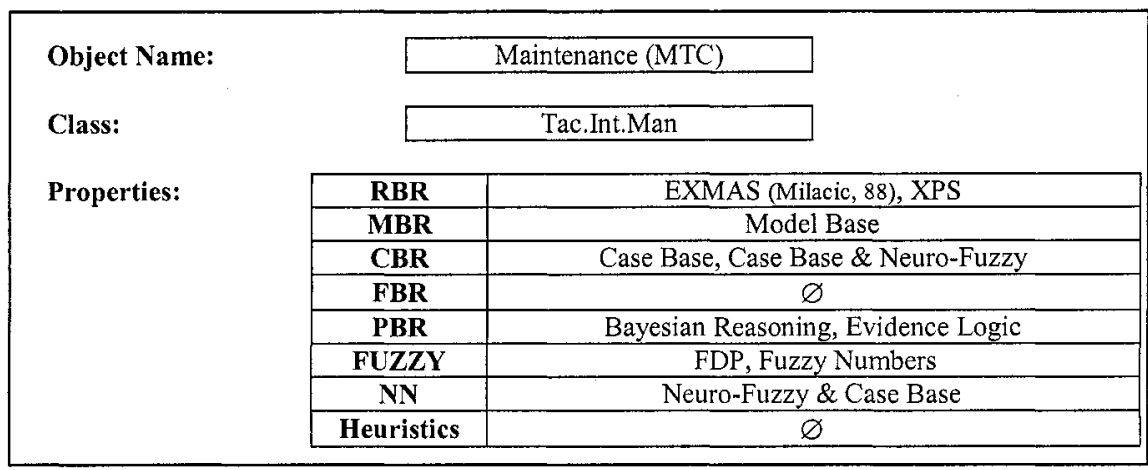

\subsection{Group Technology (GT) Frame}

Group technology (GT) is a management philosophy that attempts to group products with similar design (shape oriented) or manufacturing characteristics (process oriented) or both. One of the most important applications of GT is Cellular Manufacturing ( $\mathrm{CM}$ ). The main objective of CM is to identify machine $c$ ells and part families concurrently and to allocate part families to machine cells in a way that minimizes the intercellular movement of parts [10]. In fact, the main problem of GT (and $\mathrm{CM}$ ) is clustering and classification. Neural networks are very powerful in classification; specially ART family networks (ART1, ART2, ART MAP, fuzzy ART and so on) are used in clustering excellently [4]. Similarly, other self 
organizing neural networks such as Kohonen network can be used in classification process. As an alternative, fuzzy clustering [23] can also be used to cluster the parts.

GT can be performed using rule bases. Rules are defined such that map physical features to external shape features [22]. Meanwhile, Products can be represented as frames; then FBR may be widely used in GT process [12], such as following rules:

IF $40<$ item.length $\leq 80$ AND $15<$ item.diameter $\leq 30$ AND item.material is Alloy

steels THEN item .calss $=$ Hole family group .

Similarly, products may be made up as a case and then CBR can be used in classification process alone or with rule base [19].

In Summarize of above explanations, the frame base of "group technology" will be illustrated as follows:

\begin{tabular}{|c|c|c|}
\hline Object Name: & Group Technology (GT) & chnology (GT) \\
\hline Class: & & c.Int.Man \\
\hline \multirow[t]{8}{*}{ Properties: } & RBR & SAPT (Milacic, 87), Rule Base \& Case Base \\
\hline & MBR & $\varnothing$ \\
\hline & CBR & Case Base, Case Base \& Rule Base \\
\hline & FBR & Frame Base \\
\hline & PBR & $\varnothing$ \\
\hline & FUZZY & Fuzzy Clustering (Bezdek, 81) \\
\hline & $\mathrm{NN}$ & ART, Kohonen, Feedforward \\
\hline & Heuristics & $\varnothing$ \\
\hline
\end{tabular}

\subsection{Process \& Product Design (PPD) Frame}

Process and product design are of main duties of manufacturing, related to designing complex products and also designing production process. Globally some advanced manufacturing systems such as $\mathrm{CAD} / \mathrm{CAM}, \mathrm{CAPP}, \mathrm{CACE}$ and CAPM are categorized in this aspect.

There are a wide range of rule bases and frame bases which are developed to decide exactly how to design a part and how to manufacture it [6-7], [12], [19-24]. Followings are sample of rules (from ARL) and sample of frames (from CPMAPII) used in process and product design:

IF part $=$ hood outer AND material $=$ Aluminum Alloy AND application $=$ forming AND forming = stretch drawing THEN Guidelines = test val: left 5:right 8:line $2 "$.

\begin{tabular}{|c|c|c|}
\hline Object: & Gas Fuse & \\
\hline \multirow{4}{*}{ Properties: } & Classification & Electronic.Components \\
\hline & Identification & Through.hole \\
\hline & Shape & Axial \\
\hline & Type & Two.leads \\
\hline
\end{tabular}

The rules and frames can be defined fuzzily [8]; such as following fuzzy objectoriented rule [14]:

IF bareboard width is high AND bareboard.height is less AND bareboard.length is low THEN exterior cover \# is " $35-256$ "

Similarly, the process and product cases can be defined and then designing is performed using CBR [19]. Cases may be defined fuzzily. For example Main et. al developed fuzzy case based system along with feedforward neural network for 
fashion shoe design [18]. Finally, as marginal application, neural networks can be used in training of system designers such as NC, CNC and DNC machines [29].

In Summarize of above explanations, the frame base of "process and product design" will be illustrated as follows:

\begin{tabular}{|c|c|c|}
\hline Object Name: & \multicolumn{2}{|c|}{ Process \& Product Design (PPD) } \\
\hline Class: & & Tac.Int.Man \\
\hline \multirow[t]{8}{*}{ Properties: } & RBR & $\begin{array}{l}\text { GARI (Descote \& Lathom, 83), Proplan (Philiphs, 84), } \\
\text { CABPRO (VanDyna, 85), XCUT (Brooks, 87), } \\
\text { ARL (Demeri, 90), KDPAG (Chen \& Qin, 98) }\end{array}$ \\
\hline & MBR & $\varnothing$ \\
\hline & CBR & PDA (Bhrvani, 90), Fuzzy Case Base \\
\hline & FBR & $\begin{array}{l}\text { TIES (Ford Company), Himapp (Berenji \& khoshnevis, 86), } \\
\text { DLMS (Johnson, 89) and ISPA (Bozenhardt, 90) } \\
\text { CPMAPII (Dagnin \& Council, 90), Fuzzy Frame Base }\end{array}$ \\
\hline & PBR & $\varnothing$ \\
\hline & FUZZY & Fuzzy Rule Base, Fuzzy Frame Base, Fuzzy Case Base \\
\hline & NN & Feedforward \\
\hline & Heuristics & $\varnothing$ \\
\hline
\end{tabular}

Now, using above frame bases and based on inheritance rule the parent frame of strategic intelligent manufacturing can be illustrated as follows:

\begin{tabular}{|c|c|}
\hline \multicolumn{2}{|c|}{ Tac.Int.Man Frame } \\
\hline RBR & Rule Base, Rule Base \& Case Base \\
\hline MBR & Model Base \\
\hline CBR & Case Base, Case Base \& Rule Base, Case Base \& Neuro-fuzzy \\
\hline FBR & Frame Base \\
\hline PBR & Bayesian Reasoning, Evidence Logic \\
\hline FUZZY & Fuzzy Rule Base, Fuzzy Clustering, Fuzzy OR, Fuzzy Number, \\
\hline NN & Fuzzy Case Base, Fuzzy Frame Base \\
\hline Heuristics & ART, Hopfield, Kohonen, Neuro-fuzzy, Feedforward, Neuro-fuzzy \& Case Base \\
\hline
\end{tabular}

\section{CONCLUSIONS}

In previous sections, various frame bases are introduced based on various aspects of manufacturing. The frame bases are representative of AI applications in these aspects. Now, let suppose the frame as capsules of knowledge; then based on hieratical structure of intelligent manufacturing, following semantic networks can be developed. The arcs illustrate the attributes which are inherited. The network includes knowledge about the operation of knowledge-based systems in intelligent manufacturing; which is the same Meta knowledge. This Meta Knowledge enhances the efficiency of AI applications by directing to the most promising aspects. 


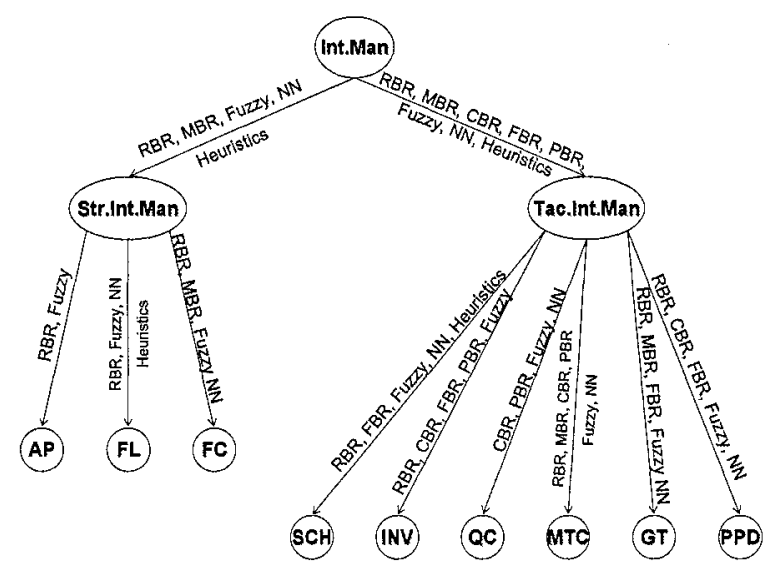

Figure 1 - Semantic network of intelligent manufacturing

Such as shown, rule based systems are approximately used in all aspects; perhaps because the rule bases are the earliest intelligent systems and naturally have found various applications. But the rule bases are symbolic knowledge bases; whilst manufacturing aspects are generally numerical. Such as shown, RBR is mostly used in SCH and PPD and also in some aspects such as MTC and AP is used marginally and auxiliary.

Unlike, fuzzy rule bases have more comprehensive structure. While the system uses linguistic variables and values, the inference is performed on numerical processing and crisp solutions can be generated. Although application of fuzzy systems is not much more than RBR, but because of data driven property and uncertainty suggestion, the growth acceleration is incrementally increasing.

Fuzzy logic provides more robust capability for vague and uncertain information. Hence, various fuzzy OR models are developed in manufacturing aspects and then solved using fuzzy arithmetic and fuzzy relations.

Other reasoning systems seem to be more causal:

- FBR is used in the aspects with hierarchical structure, such as group technology, inventory systems (i.e. MRP II and ERP) and scheduling.

- CBR on the other hand is used in the most tactical aspect; since these aspects accompany with decisional operations such as purchasing or non-purchasing, reject or accept and replacement or continue. In addition CBR have found success in the aspects related to design of products. (I.e. GT and PPD).

- The application of PBR and MBR are restricted to special conditions of related aspects.

- Similarly, Meta heuristics are generally developed in NP-Complete and NPHard problems. The numbers of paper which are published in this context is very much and the applications are expanding to the other aspects.

- Finally, the applications of NN are very different. Some optimization networks such as MNN, Hopfield and Kohonen networks are used in NP-Complete problems. Others have used in specific applications such as clustering (ART networks), forecasting (TDNN) and training the other reasoning systems (Neuro-fuzzy). 
In general speaking, while the acceleration of rule base applications is decreasing, fuzzy systems and hybrid applications have found attainable growth in various manufacturing aspects.

\section{REFERENCES}

1. Byrd TA, Hauser RD. Expert systems in production and operations management: research directions in assessing overall impact. International Journal of Production Research 1991; 29 (12): 2471-2482.

2. Dagli CH. Artificial neural networks for intelligent manufacturing. London: Chapman \& Hall, 1994.

3. Durkin J, Durkin J. Expert systems: design and development. New Jersey: Prentice Hall, 1998.

4. Frank T, Kraiss KF, Kuhlen T. Comparative analysis of Fuzzy ART and ART-2A network clustering performance. IEEE Transactions on Neural Networks May 1998; 9 (3): 544-559.

5. Fu L. Neural networks in computer intelligence. New York: McGraw Hill, 1994.

6. Gero JS. Artificial intelligence in engineering: robotics and processes. New York: Elsevier, 1988.

7. Goslar MD. Expert systems in production and operation management. Book of proceedings of the $4^{\text {th }}$ international conference, South Carolina: University of South Carolina, 1990.

8. Grabot B, Geneste L. Management of imprecision and uncertainty for production activity control. Journal of Intelligent Manufacturing 1998; 9: 431-446.

9. Haykin S. Neural network: a comprehensive foundation, Second Edition. New Jersey: Prentice Hall, 1999.

10. Heragu S. Facility design. Boston: PWS Publishing, 1997.

11. Javadpour R, Knapp GM. A fuzzy neural network approach to machine condition monitoring. Computer \& Industrial Engineering 2003; 45: 323-330.

12. Kusiak A. Expert systems: strategies and solutions in manufacturing design. Dearborn: SME Publication, 1988.

13. Leondes CT. F uzzy theory s ystems, techniques and applications, Vol. 3, 4. N ew Y ork: Academic Press, 1999.

14. Lee SC, Lee JY, Kuo YH. A framework for object-oriented fuzzy expert systems. IEEE Proceedings of NAFIPS/IFIS/NASA Dec 1994: 214-222.

15. Liebowitz J. The handbook of applied expert systems. New York: CRC Press, 1998.

16. Liu ZQ, Yan F. Fuzzy neural network in case based diagnostic system. IEEE Transactions on Fuzzy Systems May 1997, 5 (2): 209-222.

17. Luger GF. Artificial intelligence: structures and strategies for complex problem solving, Forth Edition. New York: Addison Wesley, 2002.

18. Main S, Dillon TS, Khosla R. Use of fuzzy feature vectors and neural networks for case retrieval in case based systems. Biennial conference of NAFIPS June 1996: 438-443.

19. Maus R, Keyes J. Handbook of expert systems in manufacturing. New York: McGraw Hill, 1991.

20. Meyer W. Expert systems in factory management: knowledge based CIM. New York: Ellis Harwood, 1990.

21. Metaxiotis KS, Askounis D, Psarras J. Expert systems in production planning and scheduling: A stateof-the-art survey, Journal of Intelligent Manufacturing 2002; 13: 253-260.

22. Milacic VR. Intelligent manufacturing systems, Vol. I, II, III. New York: Elsevier, 1991.

23. Oliff MD. Expert systems and intelligent manufacturing. New York: North-Holland, 1988.

24. Rzevski G. Artificial intelligence in manufacturing. New York: Springer, 1989.

25. Schenker DF, Khoshgoftaar TM. The application of fuzzy enhanced case-based reasoning for identifying fault-prone modules. Third IEEE International High Assurance Systems Engineering Symposium November 1998; 90-97.

26. Sriram RD. Intelligent systems for engineering: a knowledge based approach. London: Springer, 1997.

27. Tersine RJ. Principles of inventory and materials management, Forth Edition. New Jersey: Prentice Hall, 1994.

28. Turban E, Aronson JE, Liang TP. Decision support systems and intelligent systems, Seventh Edition. New Jersey: Prentice Hall, 2004.

29. Want J, Takefuji Y. Neural networks in design and manufacturing. New Jersey: W orld Scientific, 1993.

30. Zimmmermann HJ. Fuzzy set theory and its applications, Third Edition. Boston: Kluwer, 1996. 